\title{
Impairment of nasal mucociliary clearance in former smokers with stable chronic obstructive pulmonary disease relates to the presence of a chronic bronchitis phenotype*
}

\author{
Vladimir Koblizek ${ }^{1}$, Marketa Tomsova ${ }^{2}$, Eva Cermakova ${ }^{3}$, Petr Papousek ${ }^{1}$, \\ Sarka Pracharova ${ }^{1}$, Rajiv A.A. Mandalia ${ }^{1}$, Jiri Ceral ${ }^{4}$, Jakub Novosad ${ }^{5}$, \\ Libor Fila ${ }^{6}$, Vratislav Sedlak ${ }^{1}$, Jiri Ruta ${ }^{1}$, Vladimir Bartos ${ }^{1}$, Frantisek Salajka ${ }^{1}$, \\ Michal Hrnciarik ${ }^{1}$
Pulmonary Department, Faculty of Medicine and University Hospital Hradec Kralove, Charles University in Prague, Czech Republic University in Prague, Czech Republic Republic Charles University in Prague, Czech Republic University in Prague, Czech Republic Czech Republic \\ 2 Fingerland Department of Pathology, Faculty of Medicine and University Hospital Hradec Kralove, Charles \\ 3 Computer Technology Centre, Faculty of Medicine Hradec Kralove, Charles University in Prague, Czech \\ 4 First Department of Internal Medicine, Faculty of Medicine and University Hospital Hradec Kralove, \\ 5 Department of Clinical Immunology and Allergology, Faculty of Medicine and University Hospital, Charles \\ 6 Pulmonary Department, Faculty of Medicine and University Hospital Motol, Charles University in Prague,
}

\begin{abstract}
Background: Associations between nasal and bronchial impairment have been repeatedly described in chronic obstructive pulmonary disease (COPD), whereas nasal mucociliary clearance (MCC) in COPD patients is not yet fully understood. We studied nasal MCC parameters in COPD patients and compared them with healthy adults (HA) and with cystic fibrosis (CF) patients with compromised MCC.

Methodology: An observational study of 98 COPD ex-smokers and subjects from control groups evaluated for nasal MCC time (NMCCt) and by digital video microscopy of nasal mucosa recording ciliary beat frequency $(C B F)$ and ciliary beat pattern.

Results: The NMCCt was decreased in HA compared to those with COPD and decreased in those with COPD compared to those with CF. CBF in COPD was lower compared to $H A$. The index of ciliary dyskinesia in COPD patients differed from HA. We detected higher NMCCt and lower nasal CBF in patients with chronic bronchitis phenotype (CB) compared to non-CB patients.

Conclusions: We confirmed the presence of impaired nasal MCC in COPD ex-smokers. These impairments were apparent predominantly in the CB phenotype.
\end{abstract}

Key words: nasal epithelium, mucociliary clearance, ciliary frequency, COPD, former smokers

\section{INTRODUCTION}

Chronic obstructive pulmonary disease (COPD) is an increasing health problem ${ }^{(1)}$. The majority of COPD patients have a chronic productive cough, which is considered the chronic bronchitis $(\mathrm{CB})$ phenotype. Others never have a chronic productive cough; they constitute the non-CB phenotype ${ }^{(2-4)}$. The $\mathrm{CB}$ phenotype leads to a more pronounced progression of disease, more frequent exacerbations, faster decline of pulmonary function and a higher risk of death from pulmonary infection than in non-CB subjects ${ }^{(5-7)}$. There are several reasons for mucus retention in the $\mathrm{CB}$ phenotype. Among others, mucus clearance in COPD patients is generally considered to be modified due to the impairment of mucociliary function ${ }^{(8-11)}$. However, there are scant data concerning characteristics of ciliary respiratory epithelium in patients suffering from COPD.

Associations between nasal and bronchial impairment have been repeatedly reported suggesting that there is a co-existence 
of upper and lower airway pathology in COPD ${ }^{(12-25)}$. We used a pan-airways inflammation pattern of COPD and studied mucociliary function in the nasal area of long-term ex-smokers with stable COPD and compared them with two control groups: healthy adults (HA) as negative controls without decreased MCC and patients with cystic fibrosis (CF) as positive controls ${ }^{(8)}$. Our research examined the following hypotheses: 1) there is an impairment of nasal mucociliary clearance in COPD patients, 2) this impairment is manifested predominantly in patients with the chronic bronchitis phenotype.

\section{MATERIALS AND METHODS \\ Study Population}

Ex-smokers with COPD were selected from our out-patient file (Figure 1). Control groups included adults with cystic fibrosis (CF) and healthy adults (HA). The study was reviewed and approved by the Ethical Committee of Charles University, Faculty of Medicine in Hradec Kralove (March 11, 2004) and all subjects gave written informed consent.

\section{Methods}

An observational study was performed during the period July 2005 to June 2008. All COPD patients underwent a comprehensive examination to determine COPD severity, COPD phenotype and exclusion of an alternative diagnosis. All subjects were evaluated by two tests focusing on ciliary function: the saccharin test and digital video microscopy of nasal mucosa (see Additional File 1).

\section{Questionnaires and laboratory examination}

Each subject completed a detailed interview regarding their medical history and nasal symptoms, including the Medical Research Council (MRC) dyspnoea scale and St George's Respiratory Questionnaire (SGRQ) ${ }^{(13,24,26,27)}$. The majority of results from these questionnaires have been included in a previous article ${ }^{(28)}$. Extensive laboratory examination enabled an exclusion of alternative pulmonary diagnoses (see Additional File 1).

\section{Pulmonary function assessment}

The pulmonary function tests ( $\mathrm{PFT}^{\prime}$ s) included static and dynamic lung volumes, single breath diffusing capacity for carbon monoxide examination (DLCO) and the 6-minute walk test (6MWT). All these methods have been described previously and were performed according to the ATS/ERS recommendations and methodology (ZAN 500 Body, Messgareate GmbH, Germany) ${ }^{(29)}$.

\section{Verification of absence of active smoking}

We analysed the amount of carbon monoxide in exhaled air (Micro4 Smokerlyzer, Bedfont Scientific Ltd., UK) prior to the ciliary tests (see Additional File 1).

\section{Nasal mucociliary clearance time ( $N M C C t$ )}

NMCCt was determined by use of the saccharin test ${ }^{(30,31)}$. In short, a $1 \mathrm{~mm}^{3}$ particle of pharmacologically prepared saccharin was placed on the middle part of the superior surface of the inferior nasal turbinate. The fasting patients sat quietly, swallowed every 30 seconds until the saccharin was tasted, or until 60 minutes passed without a sweet taste. The time from saccharin particle placement to the first recognition of sweet taste was noted. The resulting NMCCt for COPD and CF subjects was calculated as the mean of two measurements carried out at the same time of day on two consecutive days under the same ambient conditions: temperature $21^{\circ} \mathrm{C}$ and humidity $60 \%$. In healthy volunteers, NMCCt was measured only once. If after 60 minutes no sweet taste was observed, we placed a new saccharin particle on the tongue to confirm whether the subject was able to taste saccharin.

\section{Digital microscopy of nasal ciliary epithelium}

Nasal epithelial strips were obtained from the superior surface of the inferior nasal turbinate using an antrum curette (Coakley 17 cm/63/4" Rudolf Medizintechnik, Germany) and were suspended in physiological saline ( $\mathrm{pH}$ 5.5, Braun, Germany) in a chamber created by the cover slip and underlying glass slide with shallow depression ${ }^{(20,31-35)}$. The slide was placed on a heated stage $\left(25^{\circ} \mathrm{C}\right)$ of a light microscope mounted on an anti-vibration table (Radwag Ltd., Poland) ${ }^{(25)}$. Specimens were examined using a dark field contrast microscope (Nikon Eclipse 80i, Japan) and a 100 x objective lens using oil immersion. Epithelial strips were recorded using a digital video camera (Sony XC HR 300, Japan) at a rate of 50 frames/sec ${ }^{(36,37)}$. Video sequences were recorded and played back at a reduced rate or frame-by-frame. Ciliary parameters were determined from ciliated epithelial cells viewed in side profile.

Ciliary beat frequency ( $\mathrm{CBF}$ ) was evaluated as previously described ${ }^{(38-40)}$. Undisrupted ciliated strips and strips with minor cellular projections both longer than $50 \mu \mathrm{m}$ devoid of mucus were studied ${ }^{(41)}$. The ciliated edge of one strip, visible on a high-resolution monitor, was divided into five adjacent areas measuring $10 \mu \mathrm{m}$. Two direct measurements of ciliary beat frequency were performed in each $10 \mu \mathrm{m}$ area resulting in 10 measurements along each ciliated strip. Approximately 5-7 strips were analysed per patient. Groups of beating cilia were identified and the number of frames required to complete 10 cycles calculated ${ }^{(40)}$.

To assess the ciliary beat pattern of each strip, we used a semiquantitative manner based on the following scoring system ${ }^{(40,42)}$. The path taken by a cilium during the beat cycle was analysed. Normal coordinated ciliary beating in a forward backward motion along the whole epithelial edge of one ciliated strip was scored as 0 (normokinesia). Dyskinesia was defined as an abnormal beat pattern that included reduced beat amplitude, stiff beat pattern, flickering or a twitching motion. Cilia that appeared to beat dyskinetically were scored from 1-3 depending on the extent of abnormal beats along the ciliary edge of epithelial strips (1 - light focal dyskinesia, 2 - moderate dyskinesia, 3 - severe dyskinesia of all cilia along 
an edge). We calculated the index of ciliary dyskinesia (ICD) as a modus ciliary beat pattern from all assessed epithelial strips. In the presence of two modes, the value closer to the median was chosen.

We also assessed the presence of akinesia or metaplastic squamous epithelium on each strip. For assessment purposes we used the simple scoring system: 0 - no akinesia or no metaplasia in all (5-7) epithelial strips from one subject, 2 - total akinesia or total metaplasia = akinesia or squamous epithelium metaplasia in all of a patient's strips, 1 - partial akinesia or partial metaplasia $=$ non total akinesia or non total metaplasia) ${ }^{(42)}$.

Two observers, a pathologist and a pulmonologist performed all ciliary measurements (blind - without any information about subjects and independently - at different times).

\section{Statistical analysis}

Numerical data is presented as mean \pm SD or as median with $95 \%$ confidence interval for median. Quantitative data is presented by counts and percentage counts. Numerical data was analysed by t-test or by non-parametric Mann-Whitney or Kolmogorov-Smirnov tests, when comparing two groups. Analysis of variance with post-hoc Fisher's LSD test or nonparametric Kruskal-Wallis ANOVA with post-hoc Dunn's test (with Bonferroni modification) was used in a case of comparing three or more groups. Qualitative data was analysed by Fisher's exact test in contingency tables. Relationship was analysed by Spearman correlation coefficients. A p-value of < 0.05 was considered statistically significant.

To compare two measurements of NMCCt, we used the BlandAltman method and Wilcoxon signed-rank test. To determine inter observer variation of CBF readings, we used a blinded fashion for both observers. Intra observer variation of $\mathrm{CBF}$ readings was done by re-analysis of the same ciliary edges on
10 separate patients by the same observer (Tomsova). Interobserver and intra-observer coefficients of variation (CV) were calculated and compared by Wilcoxon signed-rank test ${ }^{(39)}$. Computations were performed using NCSS 2007 Statistical Software (NCSS, Kaysville, UT, USA).

\section{RESULTS}

We included in the final analysis 98 ex-smokers with COPD, 15 adult CF patients and 39 HA (Table 1). COPD patients were age matched $(p=0.146)$ to HA subjects, $C F$ group members were younger $(\mathrm{p}<0.001)$.

\section{Nasal mucociliary clearance time (NMCCt)}

NMCCt was significantly ( $\mathrm{p}<0.01$ ) decreased in HA compared to COPD patients and in COPD patients $(\mathrm{p}<0.05)$ compared to $\mathrm{CF}$ subjects (Table 2). Only three healthy volunteers (HA) had NMCCt longer than 20 minutes (1200 sec). In contrast, prolonged NMCCt ( $>20$ minutes) was found in thirty-six $(37 \%)$ COPD patients and in nine $(60 \%) \mathrm{CF}$ individuals. For assessing agreement between two NMCCt measurements, we used the Bland-Altman method (see Additional File 2) and the Wilcoxon signed-rank test for difference in medians (COPD: $\mathrm{p}=0.629, \mathrm{CF}: \mathrm{p}=0.858$ ). We found only weak correlations between NMCCt and pulmonary functional parameters and prognostic indexes (Table 3 ).

\section{Ciliary beat frequency ( $C B F$ )}

Evaluation of $\mathrm{CBF}$ was completed in only 105 subjects (COPD 68, CF 9, HA 28) due to the presence of total squamous metaplasia or total ciliary akinesia in the remaining 47 subjects. Compared to the HA volunteers, the CBF gradually decreases in both the CF subjects and the COPD patients. The difference between the CBF in the COPD group and CBF in the HA group was significant $(\mathrm{p}<0.01)$. This difference did not reach significance levels in the $\mathrm{CBF}$ between COPD and $\mathrm{CF}$ groups (Table 2). No significant difference was observed for

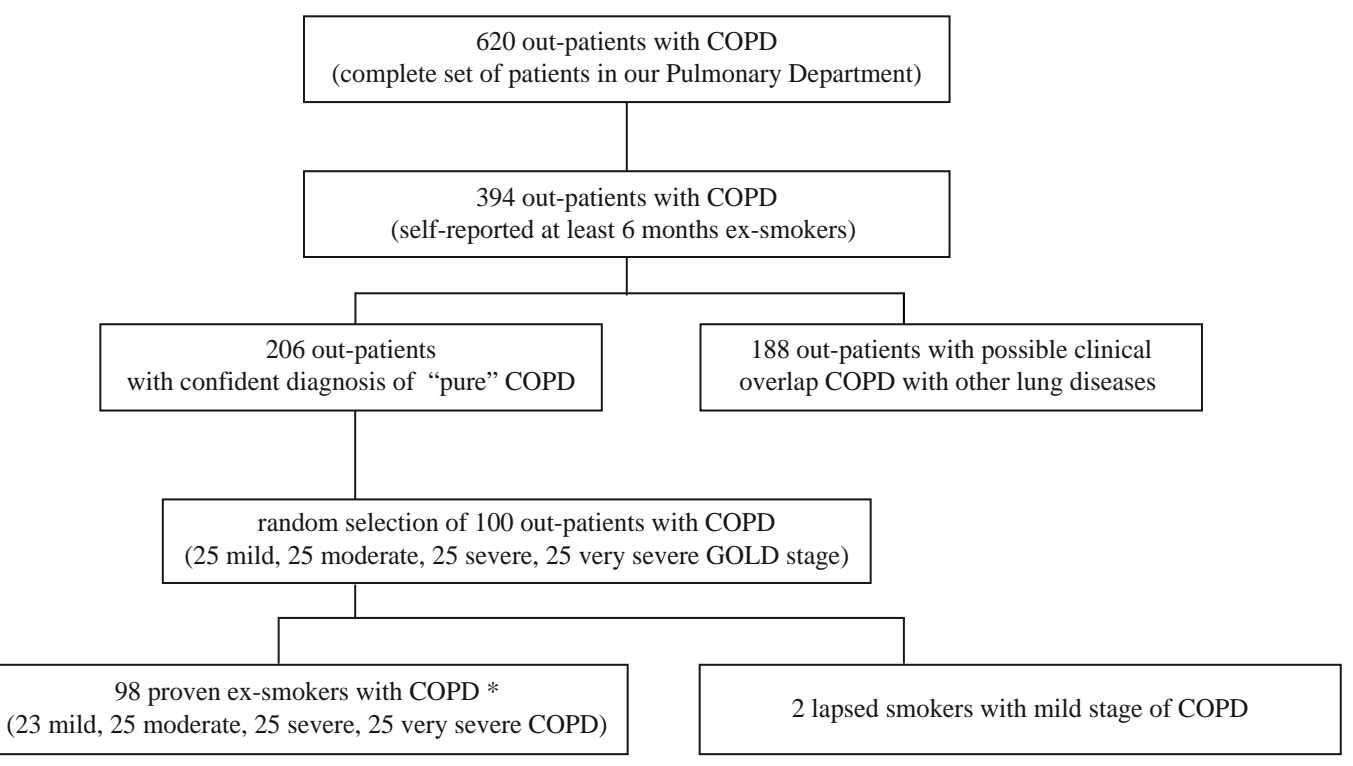

Figure 1. Trial profile shows the selection of study COPD population from our out-patients' file. ${ }^{*}$ COPD population which was finally included into this study. 


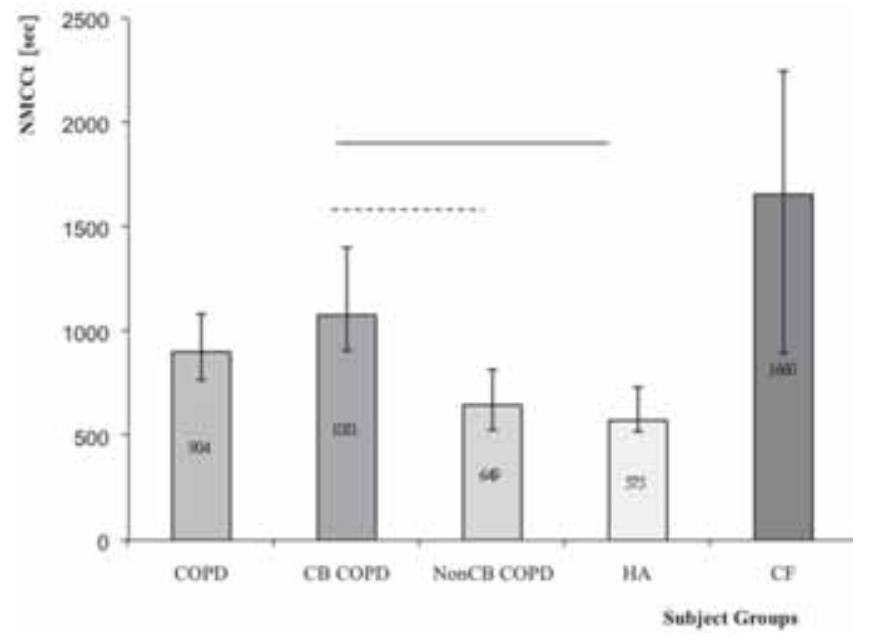

Figure 2. The measurement results of NMCCt in all examined groups (total COPD, two phenotypes of COPD, HA and CF). ---- $\mathrm{CB}$ versus non-CB phenotype Kruskal-Wallis test and Bonferroni-Dunn test $(\mathrm{p}<0.01)$. CB phenotype versus HA Kruskal-Wallis test and Bonferroni-Dunn test $(\mathrm{p}<0.001)$. Numerical data is presented as median and $95 \%$ confidence interval for median.

the inter-observer and intra-observer measurements of CV (see Additional File 3). CBF poorly correlated with pulmonary functional parameters and prognostic indexes (Table 3).

\section{Index of ciliary dyskinesia (ICD)}

ICD 0 or 1 was observed in $82 \%$ of healthy adults, $28 \%$ COPD patients and $11 \% \mathrm{CF}$ individuals. We found a significant difference $(\mathrm{p}<0.001)$ between ICD in COPD and HA groups (Table 2).

\section{Akinesia and squamous metaplasia}

The incidence of ciliary akinesia in patients with COPD reached statistical significance when compared with HA $(\mathrm{p}<0.05)$ (Table 2). The presence of nasal squamous metaplasia was comparable in all three (COPD, HA, CF) groups (Table 2).

Sub-analysis of COPD patients

$\mathrm{CB}$ and non-CB phenotypes were associated with the presence of at least two nasal symptoms in $40(62 \%)$ and $4(13 \%)$ cases, respectively. NMCCt in patients with $\mathrm{CB}$ phenotype was significantly higher than NMCCt in subjects with non-CB phenotype. The presence of prolonged NMCCt (> 20 minutes) was noted in $43.1 \%$ of $\mathrm{CB}$ individuals and in $21.2 \%$ non-CB subjects ( $\mathrm{p}<$ 0.05). Measurement of nasal CBF was carried out in $68 \mathrm{COPD}$ subjects ( $\mathrm{CB} /$ non- $\mathrm{CB}$ ratio 43/25). This could not be completed in the remaining 30 patients due to the presence of total squamous metaplasia or total ciliary akinesia. The nasal CBF of patients with $\mathrm{CB}$ phenotype was significantly lower than in non- $\mathrm{CB}$ phenotype individuals. We consistently recorded lower $\mathrm{CBF}(<6 \mathrm{~Hz})$ in patients with $\mathrm{CB}$ phenotype $(74 \%)$ compared with non-CB subjects $(16 \%)(\mathrm{p}<0.001)$ (Table 4, Figures 2,3$)$.

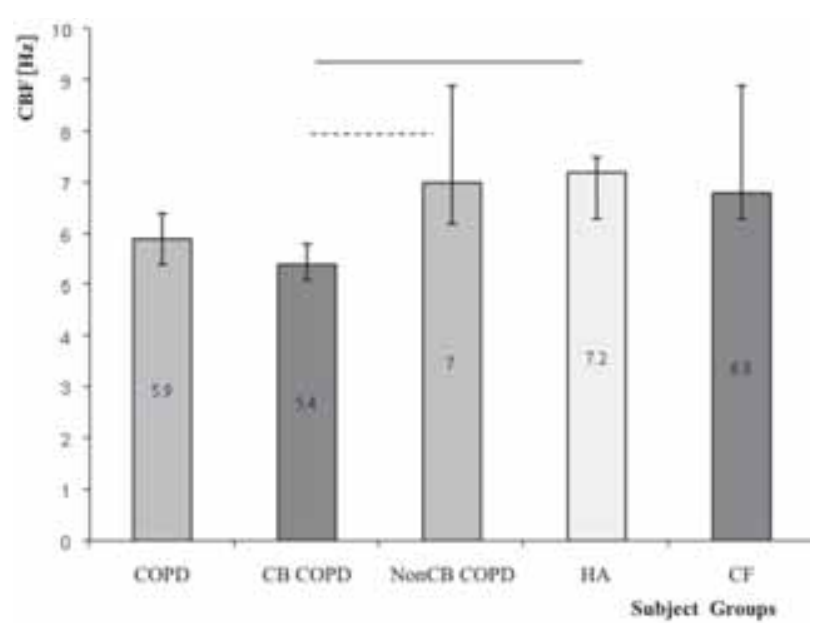

Figure 3. The comparison of nasal $\mathrm{CBF}$ in all examined groups (total COPD, two phenotypes of COPD, HA and CF). ----- $\mathrm{CB}$ versus nonCB phenotype ANOVA and Fisher's LSD test $(\mathrm{p}<0.001)$. - CB phenotype versus HA ANOVA and Fisher's LSD test $(\mathrm{p}<0.001)$. Numerical data is presented as median and 95\% confidence interval for median.

\section{DISCUSSION}

This research is based on the premise that the united-airway concept is present not only in asthma, but also in COPD. Numerous studies have provided evidence of the combination of upper and lower airway inhalation risks, gene expressions, symptoms, impaired functions and similar pathology ${ }^{(12-24)}$. In our previously reported pilot study, we found no difference in ciliary activity of nasal and bronchial mucosa of COPD patients (bronchial CBF $6.0 \mathrm{~Hz} \pm 1.3$ did not differ from nasal CBF 5.9 $\mathrm{Hz} \pm 1.3)^{(23)}$. Similar findings (with the pan-airway pattern) were reported by French and Japanese authors who compared the ultrastructural ciliary changes and MCC in the nasal and bronchial mucosa in patients with chronic bronchitis ${ }^{(12,21)}$. Nasal ciliary assessments of COPD patients are included in just a few older studies ${ }^{(43)}$. Recently, Piatti et al. studied the effects of salmeterol on nasal cilia in COPD and pneumonia patients and they confirmed the presence of lower nasal CBF $(8.64 \pm 0.9)$ in 10 younger COPD patients ${ }^{(25)}$. Vachier and colleagues established the presence of epithelial thickness, squamous cell metaplasia and pseudothickening of the basement membrane in both (nasal and bronchial) mucosa ${ }^{(15)}$. Piotrowska et al. also recently reported sino-nasal mucociliary involvement in COPD in which decreasing nasal MCC among active smokers with COPD was observed but not among former smokers with COPD ${ }^{(24)}$.

We included only former smokers to avoid the acute effects of exposure to cigarette smoke on the cilia ${ }^{(24,44)}$. Our presented COPD cohort is clearly homogeneous (patients with 'pure' COPD without any respiratory co-morbidities), additionally our COPD patients were symmetrically recruited from all four stages of disease. Our COPD patients had significantly 
Table 1. Basic demographic and clinical characteristics $(n=152)$.

\begin{tabular}{|c|c|c|c|}
\hline & COPD & HA & $\mathrm{CF}$ \\
\hline Number of subjects* & 98 & 39 & 15 \\
\hline Gender ratio $[\mathrm{male} / \mathrm{female}]^{*}$ & $79 / 19$ & $22 / 17$ & $6 / 9$ \\
\hline Age [years]* & $65.1 \pm 9.3$ & $63.2 \pm 9.6$ & $26.3 \pm 8.3$ \\
\hline Smoking status & ex-smokers $* *$ & non-smokers $* * *$ & non-smokers*** \\
\hline Nasal medication & none & none & none \\
\hline Nasal allergy & none & none & none \\
\hline Previous nasal surgery & none & none & none \\
\hline Residency & urban area & urban area & urban area \\
\hline Occupational inhalation risks & none & none & none \\
\hline Presence of acute respiratory infection & none & none & none \\
\hline Presence of chronic disease of respiratory system & COPD & none & $\mathrm{CF}$ \\
\hline Chronic expectoration"• & $65 / 98$ & $0 / 39$ & $15 / 15$ \\
\hline
\end{tabular}

*Numerical data is presented as absolute number or mean $\pm \mathrm{SD}$. **Self-reported ex-smoking status with Smokerlyzer's confirmation. ***Selfreported lifelong non-smoker with Smokerlyzer's confirmation. "and $\geq 8$ weeks free of exacerbation. "Number of patients from all group members. Note: HA were recruited from out-patients with arterial hypertension or from nurse and paramedic volunteers. CF subjects (without exacerbation) were recruited from a cohort of adult CF patients observed in our hospital.

Table 2. Mucociliary parameters of all subjects.

\begin{tabular}{|c|c|c|c|c|c|}
\hline & COPD & HA & $\mathrm{CF}$ & COPD/HA & $\mathrm{COPD} / \mathrm{CF}$ \\
\hline NMCCt $[\mathrm{sec}]^{*}$ & $\begin{array}{c}904 \\
(770,1086)\end{array}$ & $\begin{array}{c}575 \\
(522,735)\end{array}$ & $\begin{array}{c}1660 \\
(899,2253)\end{array}$ & $\mathrm{p}<0.01^{\forall}$ & $\mathrm{p}<0.05^{\forall}$ \\
\hline $\mathrm{CBF}[\mathrm{Hz}]^{*}$ & $5.9(5.4,6.4)$ & $7.2(6.3,7.5)$ & $6.8(6.3,8.9)$ & $\mathrm{p}<0.01^{\forall \forall}$ & $N S^{\forall \forall}$ \\
\hline $\operatorname{ICD}[0-3]^{* *}$ & $\begin{array}{c}0-2(2.9) \\
1-17(25) \\
2-38(55.9) \\
3-11(16.2)\end{array}$ & $\begin{array}{c}0-14(50) \\
1-9(32.1) \\
2-5(17.9) \\
3-0(0)\end{array}$ & $\begin{array}{c}0-0(0) \\
1-1(11.1) \\
2-6(66.7) \\
3-2(22.2)\end{array}$ & $\mathrm{p}<0.001^{\circ}$ & $\mathrm{NS}^{\circ}$ \\
\hline Akinesia $[0,1,2] \#$ & $\begin{array}{c}0-52(53.1) \\
1-37(37.7) \\
2-9(9.2)\end{array}$ & $\begin{array}{l}0-30(77) \\
1-7(17.9) \\
2-2(5.1)\end{array}$ & $\begin{array}{c}0-11(73.3) \\
1-4(26.7) \\
2-0(0)\end{array}$ & $\mathrm{p}<0.05^{\circ}$ & $\mathrm{NS}^{\circ}$ \\
\hline Metaplasia [0,1,2]\# & $\begin{array}{l}0-57(58.2) \\
1-19(19.4) \\
2-22(22.4)\end{array}$ & $\begin{array}{l}0-19(48.7) \\
1-11(28.2) \\
2-9(23.1)\end{array}$ & $\begin{array}{c}0-5(33.3) \\
1-6(40) \\
2-4(26.7)\end{array}$ & $\mathrm{NS}^{\circ}$ & $\mathrm{NS}^{\circ}$ \\
\hline $\mathrm{FEV}_{1}[\% \text { of predicted }]^{*} \# \#$ & $\begin{array}{c}49(44,60) \\
55.5 \% \pm 22.7\end{array}$ & $\begin{array}{l}104(100,108) \\
103.2 \% \pm 12.6\end{array}$ & $\begin{array}{c}63(35,88) \\
60.4 \% \pm 23.2\end{array}$ & $\mathrm{p}<0.001^{\forall}$ & $\mathrm{NS}^{\forall}$ \\
\hline
\end{tabular}

*Numerical data is presented as median and $95 \%$ confidence interval for median. **ICD was presented as: number of patients with modus 0 , 1, 2, 3 ( $\%$ from all group members). \# Akinesia and squamous metaplasia were presented as: number of normal (0), partial (1) and total (2) akinetic or metaplastic subjects from each group ( $\%$ from all group members). \#\# $\mathrm{FEV}_{1}$ values were also presented as mean $( \pm \mathrm{SD})$. ${ }^{\forall} \mathrm{Kruskal}$-Wallis test and Bonferroni-Dunn's test. ${ }^{\forall}$ ANOVA test and Fischer's LSD test. ${ }^{\circ}$ Fischer's exact test. Abbreviations: CBF - ciliary beat frequency, CF - cystic fibrosis patients, COPD - subjects with chronic obstructive pulmonary disease, $\mathrm{FEV}_{1}$ - forced expiratory volume in one second, HA - healthy adults, ICD - index of ciliary dyskinesia, NMCCt - nasal mucociliary clearance time, NS - non significant. 
Table 3. Relationship between ciliary parameters, pulmonary function and prognostic indexes in COPD subjects.

\begin{tabular}{lccccccc}
\hline & $\mathrm{FEV}_{1}[\%]$ & $\mathrm{RV}$ & $\mathrm{RV} / \mathrm{TLC}$ & $\mathrm{IC} / \mathrm{TLC}$ & $\mathrm{DLCO}$ & ADO & M-BODE \\
\hline $\mathrm{NMCCt}$ & -0.236 & 0.002 & 0.134 & -0.151 & -0.229 & 0.203 & 0.199 \\
$\mathrm{CBF}$ & 0.172 & 0.005 & -0.109 & 0.108 & -0.046 & -0.194 & -0.142 \\
\hline
\end{tabular}

Numerical data is presented as Spearman correlation coefficients. All correlations are only weak. Abbreviations: ADO - Age, Dyspnoea, airflow Obstruction index, M-BODE - modified Body-mass index, airflow Obstruction, Dyspnoea and Exercise capacity index, CBF - ciliary beat frequency, $\mathrm{DLCO}$ - diffusing capacity for carbon monoxide, $\mathrm{FEV}_{1}$ - forced expiratory volume in one second, IC - inspiratory capacity, $\mathrm{NMCCt}$ - nasal mucociliary clearance time, RV - residual volume, TLC - total lung capacity.

Table 4. Nasal mucociliary and functional parameters of CB and non-CB COPD subjects (sub-analysis of COPD individuals according to two basic clinical phenotypes).

\begin{tabular}{|c|c|c|c|}
\hline & CB phenotype of COPD & non-CB phenotype of COPD & $P$ value \\
\hline Number of subjects* & 65 & 33 & \\
\hline Age* & $65(60,70)$ & $64(60,69)$ & $\mathrm{NS}^{\bullet}$ \\
\hline Smoking history [pack/years]* & $30(30,35)$ & $35(28,40)$ & NS \\
\hline $\mathrm{NMCCt}[\mathrm{sec}]^{*}$ & $1081(910,1405)$ & $649(531,820)$ & $<0.01^{\bullet \bullet}$ \\
\hline $\mathrm{CBF}[\mathrm{Hz}]^{*}$ & $5.4(5.1,5.8)$ & $7.0(6.2,8.9)$ & $<0.001^{\wedge \wedge}$ \\
\hline $\operatorname{ICD}[0-3]^{* *}$ & $\begin{array}{c}0-2(4.7) \\
1-9(20.9) \\
2-25(58.1) \\
3-7(16.3)\end{array}$ & $\begin{array}{c}0-0(0) \\
1-8(32) \\
2-13(52) \\
3-4(16)\end{array}$ & $\mathrm{NS}^{\star}$ \\
\hline Akinesia $[0,1,2]^{* * *}$ & $\begin{array}{c}0-31(47.7) \\
1-28(43.1) \\
2-6(9.2)\end{array}$ & $\begin{array}{c}0-21(63.6) \\
1-9(27.3) \\
2-3(9.1)\end{array}$ & $\mathrm{NS}^{\wedge}$ \\
\hline Metaplasia $[0,1,2]^{* * *}$ & $\begin{array}{c}0-36(55.4) \\
1-13(20) \\
2-16(24.6)\end{array}$ & $\begin{array}{c}0-21(63.6) \\
1-6(18.2) \\
2-6(18.2)\end{array}$ & $\mathrm{NS}^{\wedge}$ \\
\hline $\mathrm{FEV}_{1}[\% \text { of predicted }]^{*}$ & $55(45,69)$ & $43(29,58)$ & $0.011^{\bullet}$ \\
\hline $\mathrm{RV}[\% \text { of predicted }]^{*}$ & $179(168,197)$ & $213(191,242)$ & $0.002^{\star}$ \\
\hline RV/TLC [ $\%$ of predicted $]^{*}$ & $55(51,59)$ & $60(56,66)$ & $0.010^{\wedge \wedge}$ \\
\hline IC/TLC $[\% \text { of predicted }]^{*}$ & $37(32,41)$ & $31(26,34)$ & $0.023^{\wedge \wedge}$ \\
\hline DLCO $[\%$ of predicted $] *$ & $73(62,77)$ & $54(38,69)$ & $0.005^{\wedge \wedge}$ \\
\hline
\end{tabular}

*Numerical data is presented as absolute number or median and $95 \%$ confidence interval for median. ${ }^{* *} \mathrm{ICD}$ was presented as: number of patients with modus $0,1,2,3$ ( $\%$ from all group members). ${ }^{* *}$ Akinesia and squamous metaplasia were presented as: number of normal (0), partial (1) and total (2) akinetic or metaplastic subjects from both group (\% from all group members). "Mann-Whitney test (age, smoking, FEV, RV), KolmogorovSmirnov test (NMCCt) Fisher's exact test t-test (CBF, RV/TLC, IC/TLC, DLCO). Abbreviations: CB - chronic bronchitis phenotype of COPD, CBF - ciliary beat frequency, COPD - chronic obstructive pulmonary disease, DLCO - diffusing capacity for carbon monoxide, $\mathrm{FEV}_{1}$ - forced expiratory volume in one second, IC - inspiratory capacity, ICD - index of ciliary dyskinesia, NMCCt - nasal mucociliary clearance time, NS - non significant, $\mathrm{RV}$ - residual volume, TLC - total lung capacity.

longer NMCC times, slower nasal CBF, higher nasal ICD and more frequent nasal ciliary akinesia than age matched healthy adults. CF individuals with comparable lung function had somewhat faster $\mathrm{CBF}$ than COPD patients but also suffered from prolongation of NMCC time and had higher nasal ICD (their nasal ciliary activity was less effective than in healthy individuals). Ciliary parameters of CF subjects may be related to changes in the amount and biochemical composition of nasal mucus ${ }^{(8,10)}$

Our results from ciliary measurements of healthy subjects are similar to earlier studies. Ho and co-workers showed the presence of age dependent slowdown of $\mathrm{CBF}$ and the rise of NMCCt in a cohort of adult volunteers ${ }^{(33)}$. Jorissen et al. measured the nasal CBF of elderly subjects; their results (6.7 \pm 1.7) correspond with our results ${ }^{(45)}$. 
Squamous metaplasia is a common abnormality of nasal mucosa among smokers with and without COPD or in bone marrow recipients ${ }^{(9,15,21)}$. This abnormality is related to multiple causes (especially active smoking). In contrast to Vachier, we found a similar probability of the presence of squamous metaplasia in ex-smokers with COPD, CF patients and healthy adults. The different smoking status of our COPD patients is a possible explanation. This is illustrated by the work of Lappere et al. in bronchial epithelium (46).

None of the ciliary parameters from our study correlated with staging of COPD (according to PFT's) in concert with other colleagues ${ }^{(24)}$. Chronic productive cough is an important clinical feature of a large proportion (here 66\%) of COPD patients. A somewhat smaller group (here $34 \%$ ) of people affected by COPD do not suffer from chronic expectoration. According to our results, nasal MCC impairment appears to be related more to the $\mathrm{CB}$ clinical phenotype than to disease severity. NMCCt, ciliary frequency $(\mathrm{CBF})$ and pattern (ICD) describe the different features of $\mathrm{MCC}^{(12)}$. Therefore, we are not surprised by the small correlation between ciliary parameters ${ }^{(47)}$.

This study has several limitations. In terms of methodology, we performed video microscopy and used a slower frequency (50 frames/s), we also used physiological saline with $\mathrm{pH} 5.5$ (instead of medium 199 with $\mathrm{pH}$ 7.3) and we had a lower $\left(25^{\circ} \mathrm{C}\right)$ temperature of mucosa samples than were described in majority of previous articles ${ }^{(38-40,42)}$. However slowing of cilia by cooling and decreasing of $\mathrm{pH}$ allowed detailed analysis of ciliary activity without the need for more expensive high speed video microscopy ${ }^{(25,35-37,48,49)}$. Secondly, we did not use specific questionnaires for assessment of sino-nasal symptoms (for example SNAQ-11), instead the presence of nasal involvement was detected using the four most common questions on nasal symptoms ${ }^{(24,47)}$. Finally, we have to point out that we did not have quite the same severity of airflow limitation in both subgroups of COPD patients. However, this should not affect our results given the low correlation between ciliary parameters and $\mathrm{FEV}_{1}$.

In summary, based on the current study, we suggest that COPD is associated with impaired nasal MCC. The main reasons for this association are unknown and cannot be determined from the results of the present study. COPD probably alters the ciliary beat pattern and increases the proportion of akinetic (immotile) cilia. This impairment was expressed across all GOLD stages of COPD but is more apparent in patients with the $\mathrm{CB}$ phenotype. We cannot say whether nasal parameters are in full concordance with bronchial parameters. However, this data raises the important question whether division of COPD subjects into $\mathrm{CB}$ and non-CB phenotypes will become important in clinical practice ${ }^{(50)}$. Future research in this field should include both examination of microscopic and ultrastructural epithelial alterations throughout the COPD airways and measured nasal fractional exhaled nitric oxide (FENO). This would enable us make comparison with other phenotypic differences. ACKNOWLEDGEMENTS
The authors acknowledge Catherine McGrath $\mathrm{PhD}$ for proofreading the manuscript, our nurses Katerina Zohova and Radka Vojackova for assistance and Vera Fabianova for administrative assistance; the Grant Agency of the Ministry of Health of Czech Republic [Grant NR8407-4/2005] and the Ministry of Education, Youth and Sports, Czech Republic [Grant MSM 0021620820] for financial support.

\section{AUTHORSHIP CONTRIBUTION}

VK: study design, selection of COPD subjects, sampling the nasal mucosa, ciliary evaluation (second observer - pulmonologist), writing the paper. MT: ciliary evaluation (principal observer - pathologist). EC: study design and statistical analysis. PP, SP: bibliography, selection of COPD patients, examination of patients. RM: language editing, bibliography, writing the paper. JC: selection and examination of HA subjects. JN: immunology examination of COPD subjects. LF, VS: selection of CF subjects and evaluation of sweat test and $\mathrm{CF}$ genetic analysis. JR, VB, FS, MH: examination of COPD patients.

\section{CONFLICT OF INTEREST}

VK received lecture fees from GSK (\$2000), from Boehringer Ingelheim (\$2000), from Bayer (\$2000), from Nycomed (\$2000), from Novartis (\$1000) and declares no conflicts of interest related to this article. MT, EC, SP, PP, RM, JC, FS, LF, JR, VB, FS, MH declare no conflicts of interest to this article. JN received compensation for industry-sponsored study by Quintiles (up to \$1000) and lectures fees by GSK (up to $\$ 1000$ ). He also declares that there is no conflict of interest relevant to this article. VS received lecture fees from GSK (\$1000), Boehringer Ingelheim (\$1000) and declares no conflicts of interest relevant to this article.

\section{REFERENCES}

1. Caballero A, Torres-Duque CA, Jaramillo C, el al. Prevalence of COPD in five Colombian cities situated at low, medium, and high altitude (PREPOCOL study). Chest. 2008; 133: 343-349.

2. MacNee W. Update in chronic obstructive pulmonary disease 2007. Am J Respir Crit Care Med. 2008; 177: 820-829.

3. Kim WJ, Hoffman E, Reilly J, et al. Association of COPD candidate genes with computed tomography emphysema and airway phenotypes in severe COPD. Eur Respir J. 2011; 37: 39-43.

4. Pistolesi M, Camiciottoli G, Paoletti M, et al. Identification of a predominant COPD phenotype in clinical practice. Respir Med. 2008; 102: 367-376.

5. Vestbo J, Prescott E, Lange P. Association of chronic mucus hypersecretion with FEV1 decline and chronic obstructive pulmonary disease morbidity. Copenhagen City Heart Study Group. Am J Respir Crit Care Med. 1996; 153: 1530-1535.

6. Burgel PR, Nesme-Meyer P, Chanez P, et al. Cough and sputum production are associated with frequent exacerbations and hospitalizations in COPD subjects. Chest. 2009; 135: 975-982.

7. Prescott E, Lange P, Vestbo J. Chronic mucus hypersecretion in COPD and death from pulmonary infection. Eur Respir J. 1995; 8: 1333-1338.

8. Rogers DF. Airway Mucus Secretion. In: Barnes PJ, eds. Chronic Obstructive Pulmonary Disease, Cellular and Molecular Mechanisms. Boca Raton, FL: Taylor\&Francis, 2005; 83-111.

9. Hasani A, Toms N, Agnew JE, et al. The effect of inhaled tiotropium bromide on lung mucociliary clearance in patients with COPD. Chest. 2004; 125: 1726-1734.

10. Rogers DF. Mucociliary dysfunction in COPD: effect of current pharmacotherapeutic options. Pulm Pharmacol Ther. 2005; 18: 
$1-8$

11. Bhowmik A, Chahal K, Austin G, Chakravorty I. Improving mucociliary clearance in chronic obstructive pulmonary disease. Respir Med. 2009; 103: 496-502.

12. Hattori M. Mucociliary function of chronic inflammation in upper and lower airways. Auris Nasus Larynx. 1994; 21: 219-225.

13. Montnémery P, Svensson C, Adelroth E, et al. Prevalence of nasal symptoms and their relation to self-reported asthma and chronic bronchitis/emphysema. Eur Respir J. 2001; 17: 596-603.

14. Roberts NJ, Lloyd-Owen SJ, Rapado F, et al. Relationship between chronic nasal and respiratory symptoms in patients with COPD. Respir Med. 2003; 97: 909-914.

15. Vachier I, Vignola AM, Chiappara G, et al. Inflammatory features of nasal mucosa in smokers with and without COPD. Thorax. 2004; 59: 303-307.

16. Hurst JR, Wilkinson TM, Perera WR, Donaldson GC, Wedzicha JA. Relationships among bacteria, upper airway, lower airway, and systemic inflammation in COPD. Chest. 2005; 127: 1219-1226.

17. Hurst JR, Perera WR, Wilkinson TM, Donaldson GC, Wedzicha JA. Systemic, upper and lower airway inflammation at exacerbation of COPD. Am J Respir Crit Care Med. 2006; 173: 71-78.

18. Hurst JR, Kuchai R, Michael P, et al. Nasal symptoms, airway obstruction and disease severity in chronic obstructive pulmonary disease. Clin Physiol Funct Imaging. 2006; 26: 251-256.

19. Sridhar S, Schembri F, Zeskind J, et al. Smoking-induced gene expression changes in the bronchial airway are reflected in nasal and buccal epithelium. BMC Genomics. 2008; 9: 259.

20. Escudier E, Le VT, Boucherat M, et al. Comparative frequencies of the beats of nasal and bronchial ciliary cells. Study in 10 adults without respiratory pathology. Rev Pneumol Clin. 1987; 43: 65-68.

21. Verra F, Fleury-Feith J, Boucherat M, et al. Do nasal ciliary changes reflect bronchial changes? An ultrastructural study. Am Rev Respir Dis. 1993; 147: 908-913.

22. Nihlén U, Montnémery P, Andersson M. Specific nasal symptoms and symptom-provoking factors may predict increased risk of developing COPD. Clin Physiol Funct Imaging. 2008; 28: 240-250.

23. Koblizek V, Dobesova T, Salajka F, et al. Examination of function and structure of respiratory cilia of adult patients suffering from chronic obstructive pulmonary disease - comparison of nasal and bronchial mucosa. Vnit Lek. 2009; 55: 1035-1042.

24. Piotrowska VM, Piotrowski WJ, Kurmanowska Z, et al. Rhinosinusitis in COPD: symptoms, mucosal changes, nasal lavage cells and eicosanoids. Int J Chron Obstruct Pulmon Dis. 2010; 5: 107-117.

25. Piatti G, Ambrosetii U, Santus P, Allegra L. Effects of salmeterol on cilia and mucus in COPD and pneumonia patients. Pharmacol Res. 2005; 51: 165-168.

26. Celli B, Cote C, Marin J, et al. The body-mass index, airflow obstruction, dyspnea, and exercise capacity index in chronic obstructive pulmonary disease. N Engl J Med. 2004; 350: 1005-1012.

27. Puhan M, Garcia-Aymerich J, Frey M, et al. Expansion of the prognostic assessment of patients with chronic obstructive pulmonary disease: the updated BODE index and the ADO index. Lancet. 2009; 374: 704-711.

28. Koblizek V, Salajka F, Cermakova E, et al. Relationship between quality of life and BODE index of stable ex-smokers with chronic obstructive pulmonary disease. Vnitr Lek. 2009; 55: 940-947.

29. Pellegrino R, Viegi G, Brusasco V, et al. Interpretative strategies for lung function tests. Eur Respir J. 2005; 26: 948-968.

30. Canciani M, Barlocco EG, Mastella G, et al. The saccharin method for testing mucociliary function in patients suspected of having primary ciliary dyskinesia. Pediatr Pulmonol. 1988; 5: 210-214.

31. Bush A, Chodhari R, Collins N, et al. Primary ciliary dyskinesia: current state of the art. Arch Dis Child. 2007; 92: 1136-1140.

32. Cordonnier C, Gilain L, Ricolfi F, et al. Acquired ciliary abnormalities of nasal mucosa in marrow recipients. Bone Marrow Transplant. 1996; 17: 611-616.

33. Ho JC, Chan KN, Hu WH et al. The effect of aging on nasal mucociliary clearance, beat frequency and ultrastructure of respiratory cilia. Am J Respir Crit Care Med. 2001; 163: 983-988.

34. Noone PG, Leigh MW, Sannuti A, et al. Primary ciliary dyskinesia: diagnostic and phenotypic features. Am J Respir Crit Care Med. 2004; 169: 459-467.

35. Santamaria F, de Santi MM, Grillo G, et al. Ciliary motility at light microscopy: a screening technique for ciliary defects. Acta Paediatrica. 1999; 88: 853-857.

36. Doran SA, Koss R, Tran CH, et al. Effect of serotonin on ciliary beating and intracellular calcium concentration in identified populations of embryonic ciliary cells. J Exp Biol. 2004; 207: 1415-1429.

37. Smith CM, Hirst RA, Bankart MJ, et al. Cooling of cilia allows functional analysis of beat pattern for diagnostic testing. Chest. 2011; 140: 186-190.

38. Chilvers MA, O'Callaghan C. Analysis of ciliary beat pattern and beat frequency using digital high speed imaging: comparison with the photomultiplier and photodiode methods. Thorax. 2000; 55: 314-317.

39. Chilvers MA, Rutman A, Callaghan CO. Functional analysis of cilia and ciliated epithelial ultrastructure in healthy children and young adults. Thorax. 2003; 58: 333-338.

40. Chilvers MA, McKean M, Rutman A, et al. The effects of coronavirus on human nasal ciliated respiratory epithelium. Eur Respir J. 2001; 18: 965-970.

41. Thomas B, Rutman A, O'Callaghan C. Disrupted ciliated epithelium shows slower ciliary beat frequency and increased dyskinesia. Eur Respir J. 2009; 34: 401-404.

42. Robertson A, Stannard W, Passant C, O'Callaghan C, Banerjee A. What effects does isoflurane have upon ciliary beat pattern: an in vivo study. Clin Otolaryngol. 2004; 29: 157-160.

43. Houtmeyers, E, Gosselink R, Gayan-Ramirez G, Decramer M. Regulation of mucociliary clearance in health and disease. Eur Respir J. 1999; 13: 1177-1188.

44. Agius AM, Smallman LA, Pahor AL. Age, smoking and nasal ciliary beat frequency. Clin Otolaryngol. 1998; 23: 227-230.

45. Jorissen M, Willems T, Van der Schueren B. Nasal ciliary beat frequency is age independent. Laryngoscope 1998; 108: 1042-1047.

46. Lappere TS, Sont JK, van Schadewijk A, et al. Smoking cessation and bronchial epithelial remodeling in COPD: a cross-sectional study. Respir Res. 2007; 8: 85.

47. Jorissen M. Correlations among mucociliary transport, ciliary function, and ciliary structure. Am J Rhinol. 1998; 12: 53-58.

48. Clary-Meinesz CF, Cosson J, Huitorel P, Blaive B. Temperature effect on the ciliary beat frequency of human nasal and tracheal ciliated cells. Biol Cell. 1992; 76: 335-338.

49. Clary-Meinesz CF, Mouroux J, Cosson J, Huitorel P, Blaive B. Influence of external $\mathrm{pH}$ on ciliary beat frequency in human bronchi and bronchioles. Eur Respir J. 1998; 11: 330-333.

50. Han MK, Agusti A, Calverley PM, et al. Chronic obstructive pulmonary disease phenotypes: the future of COPD. Am J Respir Crit Care Med. 2010; 182: 598-604.

\section{Vladimir Koblizek M.D.}

Department of Pneumology

University Hospital and Medical Faculty of Charles University Prague

Sokolska street 581

Hradec Kralove

Czech Republic

Tel: +420-495-83 4771

Fax: +420-495-83 4773

E-mail: koblizek@fnhk.cz 
ADDITIONAL TABLE 1.

Summary of study protocol of COPD patients (pts) and both (HA, CF) control groups.

\begin{tabular}{|c|c|c|c|}
\hline Examination & $\begin{array}{l}\text { COPD pts }(\mathrm{COPD}) \text { as } \\
\text { study group }\end{array}$ & $\begin{array}{l}\text { Healthy adults (HA) as } \\
\text { 'negative' control group }\end{array}$ & $\begin{array}{l}\text { Cystic fibrosis }(\mathrm{CF}) \text { pts } \\
\text { as 'positive' control group }\end{array}$ \\
\hline Medical history & $+\bullet$ & + & + \\
\hline Physical examination & + & + & + \\
\hline ECG & + & + & + \\
\hline Laboratory tests & + & - & $-{ }^{*}$ \\
\hline X-rays of thorax and paranasal sinuses & + & + & + \\
\hline Spirometry & $+^{* *}$ & + & $+^{* *}$ \\
\hline $\begin{array}{l}\text { Other PFTs } \\
\text { (bodypletysmography, DLCO) }\end{array}$ & + & - & + \\
\hline MRC dyspnea scale & + & - & - \\
\hline SGRQ & + & + & + \\
\hline Smokelyzer test & + & + & + \\
\hline NMCCt (saccharin test) - right nostril & + & + & + \\
\hline $\begin{array}{l}\text { Light microscopy of nasal mucosa (digital video } \\
\text { microscopy) - left nostril }\end{array}$ & + & + & + \\
\hline 6MWT & + & - & - \\
\hline
\end{tabular}

Testing was performed in the order corresponding to this Table.

+ Yes - No. With targeted questions on the occurrence of four basic nasal symptoms: blocked nose, stuffy nose, runny nose and sneezing. * Laboratory evaluation was performed previously in the CF care centre. ${ }^{* *}$ Spirometry with salbutamol bronchodilatation test. Abbreviations: CF - cystic fibrosis patients, COPD - subjects with chronic obstructive pulmonary disease, DLCO - diffusing capacity for carbon monoxide, ECG - electrocardiography, HA - healthy adults, MRC dyspnoea scale - Medical Research Council dyspnoea scale, NMCCt - nasal mucociliary clearance time, PFTs - pulmonary function tests, pts - patients, SGRQ - St. George's Respiratory Questionnaire, 6MWT - six minute walking test.

ADDITIONAL TABLE 2.

Assessing agreement between two NMCCt measurements (Bland-Altman method).

\begin{tabular}{lcccc}
\hline Examined subjects (number) & mean & SD & lower limit of agreement & upper limit of agreement \\
\hline COPD $(\mathrm{n}=98)$ & 46.3 & 465.7 & -885.1 & 977.7 \\
CF $(\mathrm{n}=15)$ & -52.8 & 1121 & -2294.8 & 2189.2 \\
\hline
\end{tabular}

Note: The Bland-Altman method calculates the mean difference between two repeated measurements, and $95 \%$ limits of agreement (mean difference $\pm 2 \mathrm{SD}$ ). These limits include $95 \%$ of differences between the two repeated measurements.

Abbreviations: $\mathrm{CF}$ - cystic fibrosis patients, COPD - subjects with chronic obstructive pulmonary disease, NMCCt - nasal mucociliary clearance time, $\mathrm{SD}$ - standard deviation. 
ADDITIONAL FILE 3.

Ciliary beat frequency $(\mathrm{CBF})$ : inter-observer and intra-observer coefficients of variation (CV).

\section{Methods}

To determine inter observer variation of $\mathrm{CBF}$ readings, cilia movie sequences from all (n 105) subjects (subjects without total akinesia or total squamous metaplasia) were re-analysed by a second observer in a blinded fashion. Thereafter intra observer variation of $\mathrm{CBF}$ readings was done by re-analysis (also in blinded fashion) of the same ciliary edges on 10 separate patients by the same observer (Tomsova - principal observer).

\section{Results}

No significant difference was observed for the inter-observer (principal observer - O1, second observer - O2) and intraobserver (first measurement of principal observer - M1, second measurement of principal observer - M2) measurements of CV. The mean (SD) CV for O1 and O2 was 18 (12.7)\% (95\% CI 15. 5 to 20.4$)$ and $18.7(13.2) \%$ (95\% CI 16.1 to 21.3$)$, respectively, and for M1 and M2 was 19.6 (14.5)\% (9.3 to 30) and 19.5 (8.2)\% (13.6 to 25.3), respectively. The mean (SD) difference in inter-observer $\mathrm{CV}$ was 0.7 (10.6)\% (95\% CI -1.3 to 2.8 ; range -25.6 to 60.6$)$ and in intra-observer $\mathrm{CV}$ was $0,14(9.96) \%$ (-7 to 7.3 ; range -20.6 to 18.9 ).

\section{ADDITIONAL FILE 4.}

List of abbreviations.

ADO index - Age, Dyspnoea, airflow Obstruction index

ATS - American Thoracic Society

BODE index - Body-mass index, airflow Obstruction, Dyspnoea and Exercise capacity index

CB phenotype - chronic bronchitis phenotype of COPD

$\mathrm{CBF}$ - ciliary beat frequency

$\mathrm{CF}$ - cystic fibrosis and/or subjects with cystic fibrosis

$\mathrm{CI}$ - confidence interval

COPD - chronic obstructive pulmonary disease

$\mathrm{CV}$ - coefficient of variation

DLCO - diffusing capacity for carbon monoxide

ECG - electrocardiography

ERS - European Respiratory Society

$\mathrm{FEV}_{1}$ - forced expiratory volume in one second

GOLD - Global initiative for chronic obstructive lung disease

HA - healthy adults

$\mathrm{Hz}-$ Hertz

IC - inspiratory capacity

ICD - index of ciliary dyskinesia

M-BODE - modified BODE index

$\mathrm{MCC}$ - mucociliary clearance

MRC dyspnoea scale - Medical Research Council dyspnoea scale

$\mathrm{NMCC}$ - nasal mucociliary clearance

$\mathrm{NMCCt}$ - nasal mucociliary clearance time

Non-CB phenotype - non chronic bronchitis phenotype of COPD

PFT's - pulmonary function tests

Pts - patients

$\mathrm{RV}$ - residual volume

$\mathrm{SD}$ - standard deviation

sec-second

SGRQ - St George's Respiratory Questionnaire

SNAQ-11 - Sino-nasal questionnaire-11

TLC - total lung capacity

$6 \mathrm{MWT}$ - six minute walking test 